ARTICLE

\title{
The role of game genres and gamers' communication networks in perceived learning
}

\author{
Chang Won Jung (iD) ${ }^{1 凶}$
}

\begin{abstract}
The present study examined the educational roles of games that were not designed for pedagogical purposes. With respect to the roles of gamers' communicationcommunication networks, network diversity, and heterogenous discussion-three specific sub-objectives of the present work include: (1) to examine the extent to which games can be social learning environments, (2) to examine how gamers' communication contributes to perceived learning, and (3) to evaluate the relationship between game genre's unique characteristics and learning effects. This work statistically tested a series of research hypotheses using empirical data obtained from a national survey of Korean gamers $(N=1392)$. The results from hierarchical multiple regression analysis indicate that game genres and gamers' communicative networks were significant predictors of perceived game learning. Importantly, game genres that are considered by policymakers to be violent and addictive were found to contribute to learning. Additionally, gamers' communication variables that are not closely related to education and politics significantly predicted their learning. Based on the results, this study suggests that game coplaying or gamers' social networks should be considered important for socio-cultural learning. Moreover, the current study provides empirical evidence that exposure to diverse perspectives during game playing contributes significantly to not only tolerance and deliberative democracy but also the sociopolitical learning of gamers. In this regard, the present study expands the literature on pedagogy (learning effects), political communication (benefits of heterogeneous/deliberative discussions), and game studies (game addiction/gaming disorder). Thus, this study provides new insights for current research on the educational roles of games.
\end{abstract}

\footnotetext{
${ }^{1}$ Yonsei University Institute for Communication Research, Seoul, South Korea. ${ }^{凶}$ email: cjung4@me.com
} 


\section{Introduction}

here has been a significant body of research to suggest that playing games explicitly designed for educational purposes provides an alternative means of teaching (Ninaus et al., 2019). For example, a recent work by Chen et al. (2019) insisted that game-based negotiation learning can promote students' goal setting. Game-based learning is characterised by balancing gaming play with subject matter or knowledge and the ability of student players to maintain the motivation of participants. It has been regarded as an educational tool of a learner-driven environment that can apply the principles or guidelines of game design to learning processes to enable student engagement in learning and their participation (Gaydos and Squire, 2012; Gee, 2003; Gee and Hayes, 2012; Jabbar and Felicia, 2015; Shapiro and Squire, 2011; Yeh and Lan, 2018).

Importantly, there is a potential to promote learning by playing games that are not designed for a pedagogical purpose. Stufft (2018) argued that the use of games that are not intrinsically designed to convey a specific concept may promote students' engagement in an interest-driven pursuit of learning knowledge. It is noteworthy to state that past literature suggests a possible positive linkage of playing games and learning in political science through the formation of network ties (Pathak et al., 2008; Freeman, 2017). The main tenet behind the educational strategy is that playing games may act as a social simulator that helps people connect with each other (building social capital), share ideas, and teach each other (collective intelligence). Moreover, literature on political communication asserts that communication or discussion significantly contributes to increasing political knowledge (Jung et al., 2011; Loy et al., 2019). While intrinsically designed game-based learning has been well recognised to be beneficial to student learning, there is no empirical documentation for the extrinsic role of game playing in the promotion of learning, particularly in the field of socio-political issues.

The current study discusses (1) to what extent games can be a learning environment, (2) how gamers' communication contributes to perceived learning of social issues, and (3) how game genre's unique characteristics relate to learning effects. As the theoretical basis, this study applies the notion of gamification on perceived game learning as discussed in pedagogical studies on game playing (Nietfeld, 2020; Park et al., 2019). In addition, the present study suggests that gamers who play certain genres (e.g. role playing or augmented reality (AR) games involving multiple players and interaction among them) are more likely to form their communication networks and discuss various political issues with others through diverse channels, as well as participate in discourse more often than other players of other game genres.

According to the results of political communication studies, communication or discussion significantly contributes to increasing political knowledge (Bennett et al., 2011; Eveland et al., 2005; Eveland and Thomson, 2006; Eveland and Hively, 2009), and thus, gamers' communication may also demonstrate learning effects. Additionally, to expand the literature on heterogeneous discussion (Mutz, 2006; Huckfeldt et al., 2004; Wojcieszak and Rojas, 2011; Kim and Hyun, 2017; Yoo and De Zuniga, 2019) and the deliberative aspect of gamers' communication, this study explores the role played by heterogeneous discussion in learning. Taken together, this study analyses the effects of three aspects of gamers' communication-communication networks, network diversity, and heterogeneous discussion-on learning of political issues. This work further validates the conceptual framework and tests a series of research hypotheses using empirical data obtained from a national survey of Korean gamers $(N=1392)$.

\section{Games as a tool for collective learning}

What is the relationship between game genres and perceived learning via game playing?. Regarding the relationship between game playing and learning, or gaming as a learning tool, the literature on game learning (gamification) provides evidence of the learning effects of game playing. Moreover, as a social consequence of game playing, Squire (2010) suggested that 'prolonged participation in game cultures may lead to a more active, problem-solving orientation to learning' (p. 2572) along with increased confidence in one's ability to foster feelings of concern. Furthermore, participation in gaming also catalyses collaborative decision-making in gamers, as reported by Beck and Wade (2004). Moreover, Halverson (2012) introduced the notion of participatory media spaces in which participants learn by performing, and proposed that such spaces serve as environments in which people can express ideas. Halverson (2012) analysed the art-creation space, whereas this study argues that gaming can be considered to provide participatory media spaces that promote teamwork and continuous interaction between players of different ages, social statuses, and other characteristics.

Kahne et al. (2013) found that online participatory activities for youth, including gaming, are increasing and creating communities, and that such activities promote understanding of the norms of membership and potentially foster collective activities. In addition, Thomas and Brown (2011) stated that 'gam[ing] does not just teach programming; it cultivates citizenship' (p. 22), and examined the collective nature of the game environment as a collection of people, skills, and talents. This collectivity is characterised by an active engagement in the process of learning or designing, with the aim of mutual learning.

With culture defined as a 'system of meaning that is shared by a social group' (Goncu and Katsarou, 2000, p. 223), Boellstorff (2008) indicated that language and other semiotic mediation in an online space serve as cultural tools that crystallise learning and development. Participating in online spaces also engages people in socialisation (Martin and Steinkuehler, 2010; Steinkuehler et al., 2012). Using this logic, people who play games acquire not only the knowledge and information required for a game, but also the behaviour patterns and communication tools that help them interact with other gamers in the community. Thus, gamers in the collective environment view each other as resources and engage in peer-to-peer learning with all members considered to be at equal positions within the community.

In fact, gamers can learn about political systems, citizenships, and real-life relationships not only by playing games that are specifically designed for this purpose as the pedagogical objective, but also by playing massively multiplayer online games (MMOGs) (Williams et al., 2006; Martin and Steinkuehler, 2010); this is because participation in gaming creates a unique culture in which the members rely on each other for completing various tasks. Williams and his colleagues (2006) analysed the guilds in World of Warcraft and found out that 'as guild size increased, guilds were also more likely to engage in more formal management and organisational practices' (p. 346), similar to real-life structures and organisations-such as political systems, hierarchies and power structures; this may be because these structures reflect not only the social constructs of organisation, but also natural human tendencies (i.e. instincts) in forming organisations. Due to these complex and formal structures in games, gamers experience opportunities for socialisation while interacting with other gamers. Moreover, by their nature, MMOGs are socially constructed worlds in which meanings are collaboratively achieved (Martin and Steinkuehler, 2010). While playing games, gamers share a social context, acquire 
opportunities for learning how to socialise with other gamers, and build a community aimed at learning.

The current study examined six game genres: role playing games (including massively multiplayer online role-playing games ([MMOGs]), multiplayer online battle arena ([MOBA]) (including Aeon of Strife), action/first person shooter (FPS)/third person shooter (TPS) (e.g. Grand Theft Auto, Overwatch, Sudden Attack, Call of Duty), strategy games, AR games (e.g. Pokémon GO), social network games and puzzles, and web board games ([SPW]) (Schroeder Publishing and Wargames). For each game genre, the top 10 games were listed based on their sales and subscriptions.

Based on the characteristics of the game genre, this study proposes the following hypotheses regarding the relationship between a specific game genre and perceived learning via gaming. As previous studies only examined the learning effects of collective-oriented game genres (role playing, MOBA, and AR games) the current study hypothesises the following relationships (see Fig. 1):

H1: Playing role playing games is positively related to perceived learning via playing games.

H2: Playing MOBA games is positively related to perceived learning via playing games.

H3: Playing AR games is positively related to perceived learning via playing games.

Because the relationships between action genre, strategy, and social network games and puzzles, and web board games ([SPW]) and learning have not been examined in previous studies, the current study examines the above associations as the research objective.

RQ1: What is the relationship between playing action games and perceived learning?

RQ2: What is the relationship between playing strategy games and perceived learning?

RQ3: What is the relationship between social network games and puzzles, and web board games ([SPW]) and perceived learning?

\section{Gamers' communication}

What is the relationship between gamers' communication and perceived learning via game playing?. According to Squire (2010), gamers' communities function as spaces for communication,

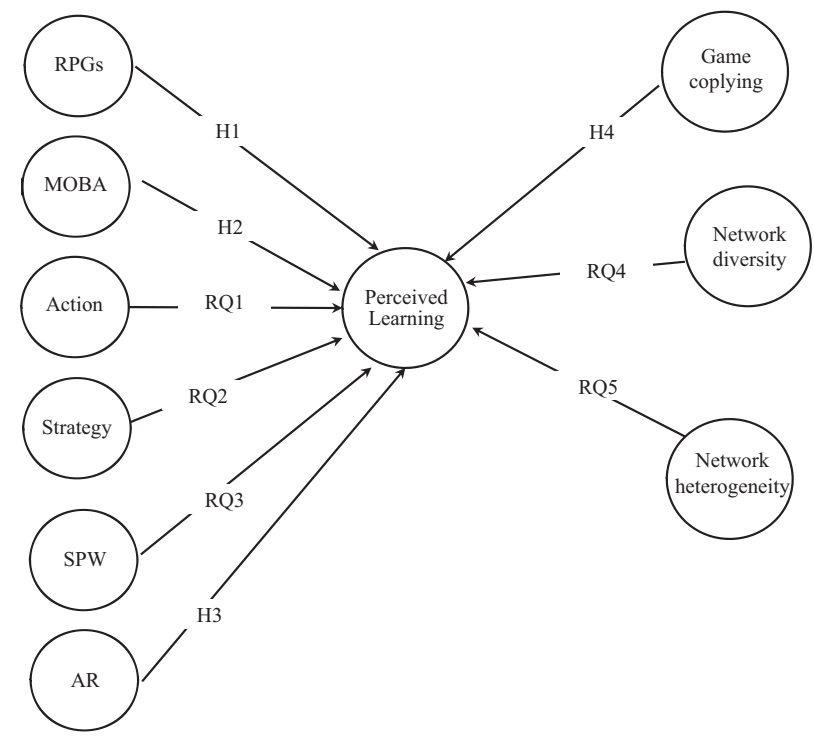

Fig. 1 Conceptual model of game genre, game copying, network diversity and network heterogeneity predicting the effect of perceived learning by playing games. which creates a learning culture for gamers. As discussed above, the collective or participatory aspects of game playing or gaming culture plays a crucial role in learning, more specifically, this study argues that communication/discussion among members has an important role in the process of learning by playing games.

Political communication studies discussed the role of communication or discussion in acquiring knowledge (Eveland et al., 2005; Eveland and Thomson, 2006; Eveland and Hively, 2009). These studies found that individuals who engage in discussions with others are more likely to acquire knowledge, which ultimately contributes to political participation. Although these studies analysed the political aspects of communication/discussion and their role in gaining political knowledge or participatory behaviour, the current study attempts to expand the relationship between communication and learning; gamers' discussion that is not thoroughly related to politics may significantly connect knowledge/learning.

Game coplaying. Apart from communication, it is also important to examine the role of communication partner/encounters. This study explores the gamers' communication networks and sources of interactions between guild members or game friends (game coplayers/coplaying). According to Yee (2006), gamer interactions are closely related to the major motivation of achievement in game playing. In other words, the social nature of engaging in the gaming culture contributes to acquiring game friendships and discussions, among others. Thus, this study argues that communication among game members through various channels of communication may contribute to building communities based on collective intelligence, and this communication is positively related to learning. Based on the previous literature, this study offers the following fourth hypothesis:

H4: Game coplaying is positively related to perceived learning via game playing.

Network diversity and heterogeneous discussion. With the large number of social networking services (SNS) available today, members of online social networks have more communication networks as well as opportunities to encounter diverse opinions that differ from their own. In social networks, likes talk to likes, ultimately leading to polarisation resulting from the reinforcement of existing views (Mutz, 2006). As such, people tend to converse with others whom they share close connections with than those who are only acquaintances, and are less likely to discuss opposing views. Moreover, according to Mutz (2006), a large network size does not guarantee diversity; people are less likely to engage in cross-cutting or heterogeneous discussions, which results in highly partisan communication while isolating individuals and significantly increasing the potential for segregation and polarisation (Sunstein, 2001, 2002).

However, this study argues that democratic citizenship requires tolerance and understanding of others' viewpoints (Bohman, 2003). Mutz (2006) suggested heterogeneous discussion as a potential solution for such segregation or polarisation. Furthermore, as a positive impact of heterogeneous discussion, Mutz (2006) found that individuals with heterogeneous discussions were aware of both the rationales for oppositional opinions and those for their own viewpoints, while demonstrating tolerance. Thus, investigating the role of heterogeneous networks in political discussions has important implications for deliberation and democratic citizenship. To expand the literature on game studies and the role of heterogeneous discussion among gamers on learning, this study raises empirical questions regarding whether the deliberative interactions (heterogeneous discussion) among discussion networks affect the perceived learning of gamers. 
As no previous study has discussed the relationship between gamers' communication networks and perceived learning via game playing, the current study offers the following research questions:

RQ4: What is the relationship between network diversity and perceived learning?

RQ5: What is the relationship between network heterogeneity and perceived learning?

\section{Methods}

The present study was conducted in compliance with the ethical guidelines of the author's university institutional review board. All participants provided written informed consent prior to the online survey.

\section{Data}

To test the perceived learning effects of game playing, an online survey was administered to Korean adults between October 26 and November 2, 2016. The study participants were selected randomly to receive the survey URL in an online invitation. Among the 2162 responses received, 403 were removed due to short response time, quitting midway, or insincere answers. The response rate was determined to be $30 \%$ by the AAPOR method version 4.0 (web). As the main study subjects, the current study focuses on gamers $(N=1362)$ who play games at present.

\section{Participants}

A total of 1362 adult Korea gamers (male $=768$, female $=594$, age range $=20-59)$ were selected. The participants provided information regarding their highest educational levels $(1=$ Elementary school; $2=$ Middle school; $3=$ High sschool; $4=$ University; $5=$ Graduate: $M=3.88$; $\mathrm{SD}=3.88)$, household annual incomes $(1=$ $<10,000,000$ won $[\sim \$ 8900] ; 2=10,000,000-20,000,000$ won; $3=20,000,000-40,000,000$ won; $4=40,000,000-60,000,000$ won; $5=60,000,000-80,000,000$ won; $6=80,000,000-100,000,000$ won; $7=$ More than $100,000,000$ won; $M=3.22 ; \mathrm{SD}=3.22$ ). The average time spent playing games by participants was between 2 and $3 \mathrm{~h}$ a day $(0=\mathrm{I}$ do not play games; $1=<1 \mathrm{~h} ; 2=$ between 1 and $2 \mathrm{~h} ; 3=$ between 2 and $3 \mathrm{~h} ; 4=$ more than $3 \mathrm{~h} ; M=2.96$; $\mathrm{SD}=0.96)$.

\section{Measurement}

Game genre. Data for the RPG genre (e.g. Lineage, World of Warcraft, Maple Story) were obtained by a single item regarding the frequency of game play, ranging from $0=$ never to $5=$ very frequently $(M=1.64, \mathrm{SD}=1.67)$. Data for the MOBA game genre (e.g. League of Legends, Heroes of the Storm) were obtained by a single item regarding the frequency of game play $(0$ $=$ never to $5=$ very frequently; $M=1.14, \mathrm{SD}=1.56$ ). Data for the strategy game genre (e.g. Civilization, SimCity, Football Manager) were acquired using a single item regarding the frequency of game play $(0=$ never to $5=$ very frequently; $M=1.51$, $\mathrm{SD}=1.71$ ). For the AR genre (e.g. Pokémon GO), data were obtained by a single item regarding the frequency of game play $(0=$ never to $5=$ very frequently; $M=2.09, \mathrm{SD}=1.80)$. Similarly, data for the SNG/Puzzle/Web board genre (e.g. Clash of Clans, Kakao Mahjong, Net Marble, Baduk) were measured through a single item regarding the frequency of game play $(0=$ never to $5=$ very frequently; $M=0.59, \mathrm{SD}=1.14$ ).

Game coplaying was considered as the combined size of game friends and guild memberships. The number of game friends was measured by an additive index of the following three items regarding the number of people that participants play with: 'Random encounters (in quest)', 'Online friends', and 'Offline friends'. An index was divided into four groups: ' 0 ' (41.4\%), ' $1-3$ '

\begin{tabular}{|lccc|}
\hline Table 1 Descriptive statistics for variables. & & \\
& Variables & M & SD \\
\hline Demographics \& game & Gender (male $=1$, & 1.44 & 1.44 \\
play hour & female =2) & & \\
& Age & 38.7 & 38.7 \\
& Education & 3.88 & 3.88 \\
& Income & 3.22 & 3.22 \\
Game genre & Game play hours & 2.96 & 0.96 \\
& RPGs & 1.64 & 1.67 \\
& MOBA & 1.14 & 1.56 \\
& Strategy & 1.51 & 1.71 \\
& Augmented reality & 2.09 & 1.8 \\
Communication networks & SNG/Puzzle/Web board & 0.59 & 1.14 \\
& Game coplaying & 1.19 & 0.96 \\
& Discussion network & 1.07 & 1.08 \\
& diversity & & \\
& Discussion network & 1.11 & 1.13 \\
& heterogeneity & & \\
Game learning & Perceived learning by & 1.43 & 1.33 \\
& playing games & & \\
\hline
\end{tabular}

(18.2\%), '4-10' (21.2\%), and ' $11-410$ ' (19.3\%) $(M=1.16$, $\mathrm{SD}=1.16)$. The number of guild members was measured using a single item on the average number of guild members with whom the respondents play. An index was divided into four groups: '0' (60.4\%), '1-6' (12.4\%), '17-20' (15.2\%), and '23-200' (12.0\%). $\quad(M=0.78, \mathrm{SD}=1.08)$. These two variables were averaged into a single index $(M=1.19, \mathrm{SD}=0.96, r=0.48)$ (Table 1).

Discussion network diversity. This study used five items to measure the discussion network diversity. The questions enquired respondents regarding their frequency of discussions during the past year with (a) guild members $(M=0.84, \mathrm{SD}=1.22)$, (b) coworkers $(M=1.07, \mathrm{SD}=1.28)$, (c) family members $(M=1.30$, $\mathrm{SD}=1.41$ ), (d) random encounters (in-quest/game; $M=0.90$, $\mathrm{SD}=1.26$ ), (e) online friends (including bloggers or community members; $M=1.00, \mathrm{SD}=1.35$ ), and (f) offline friends (e.g. friends from their neighbourhoods, schools, or workplaces) $(M=1.30, \mathrm{SD}=1.40)$. These six variables were averaged into a single index $(M=1.07, \mathrm{SD}=1.07$, Cronbach's $\alpha=0.89)$.

Discussion network heterogeneity. Respondents were asked how frequently they commented on news or discussions about politics, including game regulation with (a) people with very different ideas from your own $(M=0.96, \mathrm{SD}=1.3)$, (b) people with leftist views $(M=1.2, \mathrm{SD}=1.3)$, (c) people with rightist views $(M=1.0, \quad \mathrm{SD}=1.2)$, (d) people of a different social status $(M=1.0, \mathrm{SD}=1.2)$, and (e) people of different ages $(M=1.0$, $\mathrm{SD}=1.2)$ on a 6 -point scale. The final scale was calculated using the approach used by Scheufele et al. (2004). Respondents' selfplacement on the ideological range was used to recalculate the frequency of political discussions with ideologically like-minded individuals to 0 . In other words, a left-leaning person who discussed politics with other leftists were given a score of 0 , and similarly for right-leaning respondents. The items regarding the frequency of discussion with an individual of different social status and different political viewpoints remained unchanged because their heterogeneity was measured directly (Wojcieszak and Rojas, 2011). The final variable was calculated by averaging the mean of the five items $(M=1.1, \mathrm{SD}=1.13$, Cronbach's $\alpha=0.66$ ), with higher values indicating greater heterogeneity of discussion networks. 
Perceived learning by playing games was measured by asking respondents whether they agreed or disagreed with the following three statements: 'Through games, I have a chance to learn about socio-political systems/structures', 'Through games, I am exposed to a new world that I have not seen before', and 'Through games, I meet new people/friends to trust and share emotions with'. A 6point Likert scale was used for each item, ranging from $0=$ totally disagree to $5=$ totally agree. An index of socio-political learning by playing games was created by averaging the scores across all measures $(M=1.43, \mathrm{SD}=1.33$, Cronbach's $\alpha=0.84)$.

\section{Procedure}

A multiple hierarchical regression was performed to examine whether certain game genres and gamers' communication (networks, network diversity, and heterogeneous discussion) contribute to perceived learning. For the analysis, the demographic variables (gender, age, education, income) and game play hours of respondents were included in the first block of the equation. In the second block, the game genre variables including RPGs, MOBA, Strategy, AR, and SNG/Puzzle/Web board (SPW). In the third block, gamers' communication variables-such as game coplaying (gamers' discussion networks), discussion network diversity, and discussion heterogeneous discussion-were included.

\section{Results}

Demographics and game play hour. The model for perceived learning by game playing explained $42.7 \%$ of the variance (Table 2 ). In the first block, only game play hours $(\beta=0.369, p<0.001)$ were significant for predicting learning via game playing $(13.1 \%$ of incremental variance). The model and the $R^{2}$ change were statistically significant $(F(5,1356)=41.947, p=0.00)$. The game play hours remained significant when other variables were entered into the equation. Those who play games for longer durations tend to perceive that they acquire knowledge about socio-political issues by playing games. The age $(\beta=0.094$, $t(1361)=3.57, p<0.001)$ became significant when the game genre variables were introduced. This suggests that the effect of age is mediated by game genres and gamers' communication.

Game genre. The game genre accounted for $19 \%$ of the incremental variance. The model and the $R^{2}$ change were statistically significant $(F(6,1350)=59.390, p=0.00)$. Except for the action game genre, all game genres were significantly related to perceived learning via game playing. Nonetheless, when gamers' communicative network variables were entered into the model, role playing games $(\beta=0.081, t(1361)=3.06, p<0.01)$, MOBA $(\beta=0.103, t(1361)=3.62, \quad p<0.001)$, and AR $(\beta=0.071, t$ $(1361)=2.61, p<0.01)$ game genres contributed significantly to learning via game playing. The findings in Table 2 suggest that while the RPG, MOBA, and AR genres have a direct and indirect effect, the effect of strategy and SPW games was indirect through gamers' communication when predicting learning via game playing. Those who play RPG, MOBA, and AR genre games tend to acquire knowledge about socio-political issues via game playing. The effect of game learning was stronger in MOBA than in the RPG and AR genre.

Gamers' communicative networks. The contribution of gamers' communicative networks accounted for $10.6 \%$ of the incremental variance. The model and the $R^{2}$ change were statistically significant $(F(3,1347)=73.324, p=0.00)$. Communication variables played a significant role in predicting perceived learning. Game coplaying $(\beta=0.193, t(1361)=7.42, p<0.001)$, discussion network diversity $(\beta=0.217, t(1361)=6.78, p<0.001)$, and discussion network heterogeneity $(\beta=0.138, t(1361)=4.70, p<$ $0.001)$ were significant indicators for learning via game playing. These results indicate that those who have larger and diverse networks and engaged in discussions with others who have different viewpoints are more likely to learn via playing games. While all gamers' communicative networks were important, the effect of game learning was stronger in network diversity and game coplaying than in discussion network heterogeneity (see Figs. 2 and 3 ).

Table 2 Hierarchical multiple regression analysis model predicting perceived learning by playing games.

\begin{tabular}{|c|c|c|c|}
\hline & Block 1 & Block 2 & Block 3 \\
\hline \multicolumn{4}{|l|}{ Predictor } \\
\hline \multicolumn{4}{|l|}{ Block 1: Demographics \& game } \\
\hline Gender $($ male $=1)$ & $-0.032(-1.24)$ & $0.011(0.44)$ & $0.025(1.11)$ \\
\hline Age & $0.051(1.79)$ & $0.094^{\star \star \star}(3.57)$ & $0.085^{\star \star \star}(3.44)$ \\
\hline Education & $0.044(1.64)$ & $0.024(1.02)$ & $0.018(0.80)$ \\
\hline Income & $0.043(1.47)$ & $-0.030(-1.03)$ & $-0.045(-1.86)$ \\
\hline Game play hours & $0.369^{\star \star \star}(13.99)$ & $0.188^{\star \star \star}(7.26)$ & $0.159^{\star \star \star}(6.57)$ \\
\hline Incremental adjusted $R^{2}(\%)$ & & & $13.1^{\star \star \star}$ \\
\hline \multicolumn{4}{|l|}{ Block 2: Game Genre } \\
\hline RPGs & & $0.156^{\star \star}(5.56)$ & $0.081^{\star \star}(3.06)$ \\
\hline MOBA & & $0.166^{\star \star \star}(5.42)$ & $0.103^{\star \star \star}(3.62)$ \\
\hline Action & & $0.060(1.95)$ & $-0.011(-0.38)$ \\
\hline Strategy & & $0.084^{\star \star}(3.01)$ & $0.034(1.29)$ \\
\hline SPW & & $0.067^{\star \star}(2.78)$ & $0.027(1.23)$ \\
\hline AR & & $0.163^{\star \star \star}(5.76)$ & $0.071^{\star \star}(2.61)$ \\
\hline Incremental adjusted $R^{2}(\%)$ & & & $32.1^{\star \star \star}$ \\
\hline \multicolumn{4}{|l|}{ Block 3: Communicative networks } \\
\hline Game coplaying & & & $0.193^{\star \star \star}(7.42)$ \\
\hline Discussion network diversity & & & $0.217^{\star \star \star}(6.78)$ \\
\hline Discussion network heterogeneity & & & $0.138^{\star \star \star}(4.70)$ \\
\hline Incremental adjusted $R^{2}(\%)$ & & & $10.6^{\star \star \star}$ \\
\hline Total adjusted $R^{2}(\%)$ & & & 42.7 \\
\hline
\end{tabular}




\section{Discussion}

This study examined whether playing a specific game genre and gamers' communication networks contribute to perceived learning via playing games. The findings of this study provide empirical evidence that game genres and gamers' communicative networks are significant predictors of perceived game learning. It is noteworthy that game genres that policymakers are concerned about due to their violent content and tendency for addiction, such as RPG and MOBA games, were in reality found to contribute to learning. Moreover, the results of this study expand the literature on pedagogy, political communication, and game studies, and the variables that were not closely related to education and politics significantly predicted learning via game playing. Similar to previous studies on the new/emerging media's roles (especially SNSs usage and discussions) in participatory behaviour, the present study's findings indicate that gamers' communication networks play a significant role in game learning.

Regarding the demographic characteristics and how they predict perceived game learning, older people were found to be more likely to perceive that they learn about socio-political systems

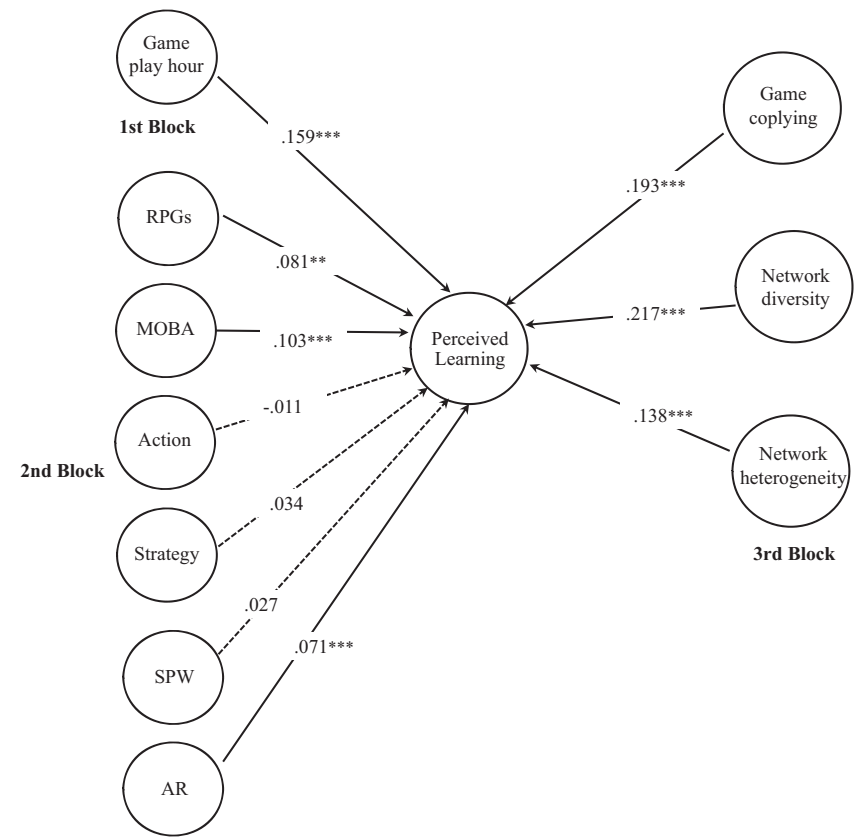

Fig. 2 Standardized regression coefficients for the relationship between game play hour, game genre, game copying, network diversity, network heterogeneity and perceived learning by playing games. ${ }^{*} p<0.05$, ${ }^{\star \star} p<$ $0.01,{ }^{\star \star \star} p<0.001 ; N=1362$. through playing games. Although the current study only sampled an adult population, one had expected a negative or insignificant relationship between age and learning (i.e. younger people would learn more or at least perceive themselves as learning more about socio-political systems via gaming). This result suggests that there are no age restrictions for learning about society and politics through playing games.

Game playing was found to be significantly related with perceived game learning. The present study's results suggest that playing RPG, MOBA, and AR game genres has social learning effects, as these genres both directly and indirectly affected learning, further implying that playing these genres encompasses a socio-political learning process. As argued in previous studies, RPGs (including MMORPGs) play a socialising role for gamers (Steinkuehler, 2006; Williams et al., 2006; Martin and Steinkuehler, 2010), and playing MMORPGs also has a critical role in learning. More specifically, Steinkuehler (2006, 2008) claimed that MMOGs provided naturally occurring learning environments that involve cognitive/participatory learning communities, which are associated with 'reciprocal forms of teaching and learning that occur in all directions throughout the social network' (p. 43). Furthermore, Steinkuehler (2006) argued that 'MMOGs are social simulations' (p. 44); in other words, MMOGs promote social communities that involve building relationships among individuals and groups.

The MOBA and AR game genres share similar characteristics, such as requiring cooperativeness and teamwork among game players. Therefore, it is possible that such collective or partyoriented characteristics of gaming communities offer gamers a culture of learning (Boellstorff, 2008) and encourage the learning effect. Thus, RPG, MOBA, and AR game quests can be considered to provide learning environments in which shared meanings are collaboratively achieved (Martin and Steinkuehler, 2010), gamers socialise with others, and build a community for learning.

Most importantly, this study found out that communication among gamers facilitates the perceived learning effects, as examined by political communication scholars (Eveland et al., 2005; Eveland and Thomson, 2006; Eveland and Hively, 2009). Game coplaying as significant gamers' social network amplified learning. While some studies argued that peer groups or gaming friends influence gaming disorder/addiction or excessive game playing (e.g. Amialchuk and Kotalik, 2016; Gunuc, 2017), the current study suggests that game coplaying or gamers' social networks should be considered one of the key conditions for socio-cultural learning.

Gamers who engage in diverse discussion networks and discussion involving various views tend to learn more by playing games. This idea implies that heterogeneous network discussion

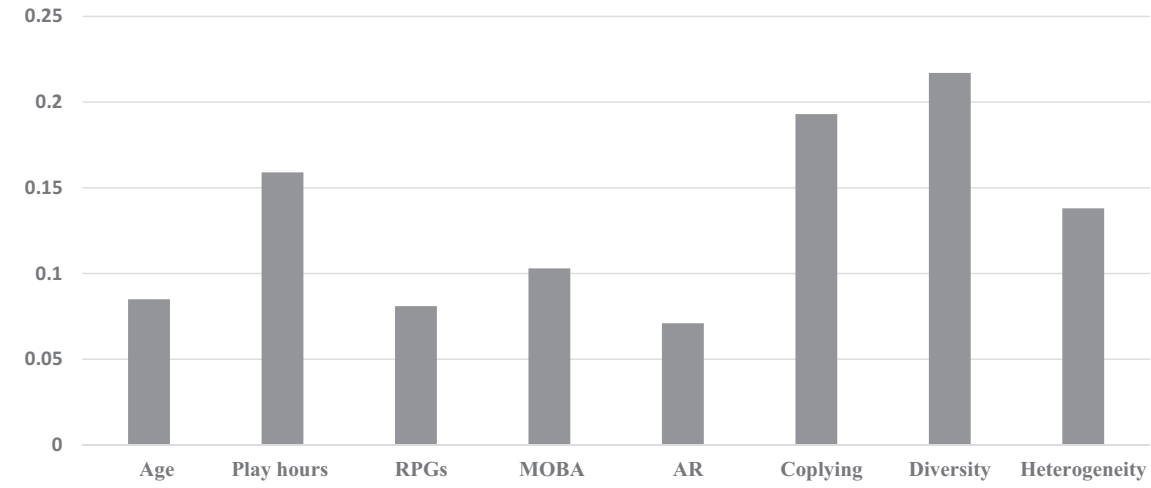

Fig. 3 Standardized regression coefficients for the relationship between age, game play hour, RPGs, MOBA, AR, game copying, network diversity, network heterogeneity and perceived learning by playing games. 
does not only positively influence tolerance as indicated by Mutz (2006), but also positively influences socio-political learning. Based on this empirical finding, the notion of the benefits of heterogeneous/deliberative discussions can be expanded and reconceptualised by analysing the over-normative argument as an important factor for gamers' learning. Thus, if modern communication media offer new channels for discussion and education in democratic processes, then the newly emerging media of games also play a critical role in this dynamic.

While many communication studies have highlighted the negative aspects of game playing, the present study provides meaningful findings regarding the positive effects of gaming. Moreover, the present study's findings clarify the importance of gamers' communication networks for learning. Guild members, online friends, and people who play games together can all be considered important resources for learning. Additionally, the current study provides empirical evidence that exposing diverse viewpoints greatly contributes to not only tolerance, but also perceived learning. It is believed that heterogeneous network discussion is an important element of social integration in a polarised society as well as for perceived learning via playing games. In this regard, the results of this study provide new insights for academia and scholars who study games in the context of violence or addiction.

While the present study mainly focused on positive aspects of game playing, the researchers also realise that game playing may have negative impacts for a vulnerable group of young children. For a small percentage, excessive game playing is detrimental to psychological status (e.g. depression, anxiety, stress) or mental health (Frölich et al., 2016; Lee and Morgan, 2018; Oskenbay et al., 2016). Some studies found that self-control or parents' support are key mediators/moderators to prevent game addiction or gaming disorder (Şahin et al., 2019; Soh et al., 2018; Zhu et al., 2015). Further research into all aspects of gaming would provide meaningful information to assist parents, schools, policymakers, and government health agencies in creating guidelines that promote prosocial gaming while allowing for intervention when gaming has become a negative issue for a particular group.

Regarding policy campaigns to prevent excessive game playing, this study offers in-depth insights into characteristics of a specific game genre. For instance, compared to the other gaming genres, RPG and MOBA gamers are multifaceted gamers who tend to consider various aspects both inside and outside of game play. Policymakers should consider the unique characteristics of the game genre and game players. In addition, as this study suggests, policymakers or those who design campaigns should understand that players of each genre have unique characteristics and gamers' interpersonal communication networks play positive roles. An identical campaign or policy may not work in a complex gaming world. Thus, policymakers should deeply understand the nature of games and gamers' communicative networks to effectively prevent negative gaming disorder.

\section{Conclusion}

Several previous studies on game learning explored the positive impacts of educationally predesigned games on learning. However, this study found that playing games of artificially violent and hypothetically addictive genres has educational effects. The current study provides new insights for current research on the educational roles of games. In addition, the findings of present study indicate that contrary to certain governments (e.g. those of China, Korea, or Vietnam) and media scholars who consider games to be violent or addictive, several critical aspects of games facilitate learning among gamers.

\section{Data availability}

The datasets analysed during the current study are available in the Dataverse repository: https://doi.org/10.7910/DVN/KPD8UN, Harvard Dataverse.

Received: 18 December 2019; Accepted: 18 March 2020; Published online: 24 April 2020

\section{References}

Amialchuk A, Kotalik A (2016) Do your school mates influence how long you game? Evidence from the US. PLoS ONE 11(8):1-16

Beck JC, Wade M (2004) Got game. Harvard Business School Press, Boston

Bennett WL, Wells C, Freelon D (2011) Communicating civic engagement: contrasting models of citizenship in the youth web sphere. J Commun 61 (5):835-856

Boellstorff T (2008) Coming of age in Second Life: an anthropologist explores the virtually human. Princeton University Press

Bohman J (2003) Deliberative toleration. Polit Theory 31(6):757-779

Chen ZH, Lu HD, Chou CY (2019) Using game-based negotiation mechanism to enhance students' goal setting and regulation. Comput Educ 129:71-81

Eveland WP Jr, Hayes AF, Shah DV et al (2005) Understanding the relationship between communication and political knowledge: a model comparison approach using panel data Polit Commun 22(4):423-446

Eveland WP Jr, Hively MH (2009) Political discussion frequency, network size, and 'heterogeneity' of discussion as predictors of political knowledge and participation J Commun 59(2):205-224

Eveland WP Jr, Thomson T (2006) Is it talking, thinking, or both? A lagged dependent variable model of discussion effects on political knowledge Commun 56(3):523-542

Freeman ME (2017) Pushing the envelope of pedagogical gaming: dark networks. PS Polit Sci Polit 50(4):1083-1088

Frölich J, Lehmkuhl G, Orawa H, Bromba M, Wolf K, Görtz-Dorten A (2016) Computer game misuse and addiction of adolescents in a clinically referred study sample. Comput Hum Behav 55:9-15

Gaydos MJ, Squire KD (2012) Role playing games for scientific citizenship. Cult Stud Sci Educ 7(4):821-844

Gee JP (2003) What video games have to teach us about learning and literacy. Edu Train 46(4):175-178

Gee JP, Hayes E (2012) Nurturing affinity spaces and game-based learning. In: Miller C, Doering A (eds) The new landscape of mobile learning: redesigning education in an app-based world. Routledge, New York

Goncu A, Katsarou E (2000) Constructing sociocultural approaches to literacy education. Play and literacy in early childhood. Lawrence Erlbaum, Mahwah

Gunuc S (2017) Peer influence in internet and digital game addicted adolescents: Is Internet/Digital Game Addiction Contagious? Int J High Risk Behav Addict 6:e33681

Halverson ER (2012) Participatory media spaces: a design perspective on learning with media and technology in the twenty-first century. In Steinkuehler C, Squire K, Barab S (eds) Games, learning, and society: learning and meaning in the digital age. Cambridge University Press

Huckfeldt R, Mendez JM, Osborn T (2004) Disagreement, ambivalence, and engagement: the political consequences of heterogeneous networks. Polit Psychol 25(1):65-95

Jabbar AIA, Felicia P (2015) Gameplay engagement and learning in game-based learning a systematic review. Rev Educ Res 85(4):740-779

Jung N, Kim Y, De Zúñiga HG (2011) The mediating role of knowledge and efficacy in the effects of communication on political participation. Mass Commun Soc 14(4):407-430

Kahne J, Lee NJ, Feezell JT (2013) The civic and political significance of online participatory cultures among youth transitioning to adulthood. J Inf Technol 10(1):1-20

Kim J, Hyun KD (2017) Political disagreement and ambivalence in new information environment: exploring conditional indirect effects of partisan news use and heterogeneous discussion networks on SNSs on political participation. Telemat Inform 34(8):1586-1596

Lee GL, Morgan H (2018) Understanding children's attraction toward digital games and preventing their gaming addiction. US-China Educ Rev A 8:11-17

Loy LS, Masur PK, Schmitt JB, Mothes C (2019) Psychological predictors of political Internet use and political knowledge in light of the perceived complexity of political issues. Inf Commun Soc 22(12):1733-1750

Martin C, Steinkuehler C (2010) Collective information literacy in massively multiplayer online games. E-learn Digit Media 7(4):355-365

Mutz DC (2006) Hearing the other side: deliberative versus participatory democracy. Cambridge University Press 
Nietfeld JL (2020) Predicting transfer from a game-based learning environment. Comput Educ 146, https://doi.org/10.1016/..compedu.2019.103780

Ninaus M, Greipl S, Kiili K et al. (2019) Increased emotional engagement in gamebased learning - A machine learning approach on facial emotion detection data. Comput Educ 142:103641

Oskenbay F, Tolegenova A, Kalymbetova E, Chung MC, Faizullina A, Jakupov M (2016) Psychological trauma as a reason for computer game addiction among adolescents. Int J Environ Sci Educ 11:2343-2353

Park J, Kim S., Kim A, Yi M Y (2019) Learning to be better at the game: Performance vs. completion contingent reward for game-based learning. Comput Educ 139:1-15

Pathak N, Mane S, Srivastava J et al. (2008) Analysis of social networks \& group dynamics from electronic communication. Next generation of data mining, Taylor and Francis

Sahin M, Keskin S, Yurdugül H (2019) Impact of family support and perception of loneliness on game addiction analysis of a mediation and moderation. Int $J$ Game-Based Learn 9:15-30

Scheufele DA, Nisbet MC, Brossard D, Nisbet EC (2004) Social structure and citizenship: Examining the impacts of social setting, network heterogeneity, and informational variables on political participation. Polit Commun 21:315-338

Shapiro RB, Squire KD (2011) Games for participatory science: a paradigm for game-based learning for promoting science literacy. Educ Technol 51(6):34-43

Soh PC, Chew KW, Koay KY, Ang PH (2018) Parents vs peers' influence on teenagers' Internet addiction and risky online activities. Telemat Inf 35:225-236

Squire K (2010) From information to experience: place-based augmented reality games as a model for learning in a globally networked society. Teach Coll Rec 112(10):2565-2602

Squire K (2011) Video games and learning: teaching and participatory culture in the digital age. Teachers College Press, New York

Steinkuehler CA (2006) Massively multiplayer online video gaming as participation in a discourse. Mind Cult Act 13(1):38-52

Steinkuehler CA (2008) Cognition and literacy in massively multiplayer online games. In: Coiro J, Knobel M, Lankshear C, Leu DJ (eds). Handbook of research on new literacies. Routledge, pp. 611-634

Steinkuehler CA, Squire K, Barab S (eds) (2012) Games, learning, and society: learning and meaning in the digital age. Cambridge University Press

Stufft CJ (2018) Engaging students in literacy practices through video game book groups. LR:TMP 67:195-210

Sunstein CR (2001) The daily we. Boston Rev 26(3):1-13

Sunstein CR (2002) Republic.com 2.0. Princeton University Press, Princeton, NJ

Thomas D, Brown JS (2011) A new culture of learning: cultivating the imagination for a world of constant change. CreateSpace, Lexington

Williams D, Ducheneaut N, Xiong L et al. (2006) From tree house to barracks: the social life of guilds in World of Warcraft. Games Cult 1(4):338-361
Wojcieszak M, Rojas H (2011) Hostile public effect: communication diversity and the projection of personal opinions onto others. J Broadcast Electron 55(4):543-562

Yee N (2006) The demographics, motivations, and derived experiences of users of massively multi-user online graphical environments. Presence-Teleop Virt 15(3):309-329

Yeh YL, Lan YJ (2018) Fostering student autonomy in English learning through creations in a 3D virtual world. ETRD 66(3):693-708

Yoo SW, De Zuniga HG (2019) The role of heterogeneous political discussion and partisanship on the effects of incidental news exposure online. J Inf Technol Politics 16(1):203-235

Zhu J, Zhang W, Yu C, Bao Z (2015) Early adolescent Internet game addiction in context: how parents, school, and peers impact youth. Comput Hum Behav 50:159-168

\section{Competing interests}

The author declares no competing interests.

\section{Additional information}

Correspondence and requests for materials should be addressed to C.W.J.

Reprints and permission information is available at http://www.nature.com/reprints

Publisher's note Springer Nature remains neutral with regard to jurisdictional claims in published maps and institutional affiliations.

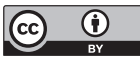

Open Access This article is licensed under a Creative Commons Attribution 4.0 International License, which permits use, sharing, adaptation, distribution and reproduction in any medium or format, as long as you give appropriate credit to the original author(s) and the source, provide a link to the Creative Commons license, and indicate if changes were made. The images or other third party material in this article are included in the article's Creative Commons license, unless indicated otherwise in a credit line to the material. If material is not included in the article's Creative Commons license and your intended use is not permitted by statutory regulation or exceeds the permitted use, you will need to obtain permission directly from the copyright holder. To view a copy of this license, visit http://creativecommons.org/ licenses/by/4.0/.

(C) The Author(s) 2020 